\title{
A STUDY ON THE WOVEN CONSTRUCTION OF FABRIC DYED WITH NATURAL INDIGO DYE AND FINISHING FOR APPLYING TO PRODUCT DESIGN FOR HOME TEXTILE PRODUCTS
}

\author{
Rungsima Chollakup ${ }^{1,4}$, Nattadon Rungruangkitkrai², Thanyachol Apipatpapha1, Suteera Witayakran ${ }^{1}$, \\ Nattawat Nithithongsakol ${ }^{3}$, and Rattanaphol Mongkholrattanasit ${ }^{4 *}$
}

1 Kasetsart Agricultural and Agro-Industrial Product Improvement Institute, Kasetsart University, Bangkok 10900, Thailand; 2 Department of Textile Science, Faculty of Agro-Industry, Kasetsart University, Bangkok 10900, Thailand;

3 Natural Niche Co., Ltd., Bangkok 10150, Thailand;

4 Department of Textiles Chemistry Technology, Faculty of Industrial Textiles and Fashion Design, Rajamangala University of Technology Phra Nakhon, Bangkok 10300, Thailand

* Corresponding authors: rattanaphol.m@rmutp.ac.th

\begin{abstract}
:
This research aims to study woven fabric construction with natural indigo dyeing with finishing for home textile applications. The physical and mechanical properties, including color fastness tests, of these woven fabrics according to ISO standards for home textiles exported to the European Union were characterized. Tensile strength, tear strength, and pilling resistance of these woven fabrics were appropriate to design, and had enough strength for bed linens, duvet covers, and pillowcases. The color fastness to washing, water, and light of these woven fabrics passed the requirements for bed linens and pillowcases, except for color fastness to wet rubbing, due to the low performance of natural dyestuff. Thus, a finishing technique of water repellency was applied to improve these properties. This design of natural fiber fabrics dyed with natural indigo was developed for home textile products whose fabrics were produced by community enterprise. These home textile products can be used as a collection prototype for a spa room in a hotel.
\end{abstract}

\section{Keywords:}

Color fastness, home textiles, indigo dyeing, physical and mechanical properties, woven fabric

\section{Introduction}

Handwoven fabric dyed with natural indigo dye is distinctive of Sakon Nakhon of Thailand, a principal location for cultivation of natural indigo. Today, few natural indigo dyed products of good quality can be found in the markets. Good quality indigo dyed fabric is characterized by color fastness to washing, with no color staining after washing and having no remaining indigo dust in the fabric. These qualities depend on the quality of raw materials used in production as well as the knowledge and expertise of the producers. At present, it can be seen that the majority of natural indigo dyed products are apparel, shawls, and scarves. The market for these products is very competitive. In addition, several studies on the application of a chemical reducing agent with an environmentally friendly process replaced the use of natural indigo dye, in order to better suit the indigo dyeing process for mass production. The indigo dyeing process has been modified from the traditional indigo dyeing method, using indigo paste in the dyeing process, to using industrial tools. This method enables an increase in the production of indigo dyed home textile products. The natural indigo dyeing processes at the community level are the vat dyeing method (mixing indigo paste with $\mathrm{NaOH}$ solution), and then later soaking the yarn in the indigo vat. This method has the problem of penetration of indigo into the yarn fibers, which may cause the dye color to be uneven. Sun drying, the traditional method, could mean that indigo dyed yarns would have dust from slaked lime in the yarn; the persons who dye the yarn might then inhale this dust, which is hazardous to health. Therefore, the dyeing method using natural indigo has been further developed: separating a clear solution of leuco indigo (reduced indigo) by lime sedimentation after mixing with the alkaline solution. The clear leuco indigo solution is then used for dyeing. The color of indigo from the clear solution can penetrate into the yarn fiber structure better than that of the indigo vat method. Sodium hydrosulfite $\left(\mathrm{Na}_{2} \mathrm{~S}_{2} \mathrm{O}_{4}\right)$ is a reducing agent with sodium hydroxide $(\mathrm{NaOH})$ solution, and adjusts the $\mathrm{pH}$ towards the alkaline region of 2 . This enables leuco indigo to more effectively penetrate into the fibers [1]. Therefore, Mongkholrattanasit et al. [2] modified the natural indigo dyeing method using the indigo vat to the dyeing process of indigo white, which uses reducing agents. This results in a better penetration and more consistency of dyestuff in the fabric, and thus is able to reduce the time required for indigo dyeing. Fabric products can have the dark indigo color within 2-3 days and with only four instances of repeat dyeing. This technique will enable small and medium enterprises (SMEs) to be able to perform the indigo dyeing process in mass production.

Recently, a research study [3] on indigo dyeing of cotton using the exhaust method indicated that using indigo to dye cotton fibers requires a continuous process of immersing cotton yarns six times in order to obtain the dark color. The process required a dyeing period of one minute and stirring for two minutes before the same procedure could be repeated. This process 
was for dyeing with reduced indigo at low temperature in order to set the dyestuff in the cotton fibers. Lately, there had been consumer need for the indigo dyeing process using the exhaust method in the garment industry. In fact, indigo dyeing with this method gives a low color yield. Thus, the cationic modification has been employed to change the surface charge of cellulosic fibers with a hydroxyl group in order to improve cationic activities of cellulose fibers, and reduce electrostatic repulsion of negative ions, resulting in a positive effect on absorption of anionic dyes and polyelectrolytes [3]. This is done using tertiary amino or quaternary ammonium cationizing reagents $[4,5]$. In addition, Wittayakarn et al. [6] used glucose as an indigo reducing agent: indigo blue was reduced in the alkaline-based solution and turned into a colorless solution, called indigo white. Furthermore, other studies investigated the application of natural reducing agents for natural indigo dyeing, such as apple, banana, dates [7], Bokbunja (Rubus coreanus) sludge [8], or persimmon (Diospyros kaki L.) peel extract [9]. They were found that dyeing reactions can be controlled better than that of the traditional method. However, the color intensity and the period of dyeing time still need to be controlled. Moreover, there have been studies on the impact of the use of the reducing agent thiourea dioxide, a useful reducing agent for vat dyes (sulfur dyes), in a closed vessel in an atmosphere of reduced oxygen level, and then oxidizing the solution, compared to sodium hydrosulphite [10]. Thiourea dioxide reducing agent is environmentally friendly and also has an important strong point of not being easily decomposed compared to traditional sodium hydrosulfite-based reducing agents when in contact with moisture. Thiourea dioxide can discharge more heat and gas than sodium hydrosulfite at high temperature [11]. It means that thiourea dioxide has good heat resistance stability, and its decomposition rate is milder than that of sodium hydrosulfite, even in a high temperature $\left(80-100^{\circ} \mathrm{C}\right)$. During the indigo dyeing process, it avoided the effluent problems associated with sodium hydrosulfite; thiourea dioxide caused less injury to fiber and less fiber loss. Concerning environment and safety, thiourea dioxide after decomposition is fully biodegradable, with no pollution of irritating gas and sulfurous odors compared to sodium hydrosulfite. The high reduction potential $(-1340 \mathrm{mV})$ of thiourea dioxide makes it more economic and efficient. Furthermore, it has the ability to provide better color fastness than glucose, which is a reducing agent used in the chemical indigo industry and also environmentally friendly. This study uses thiourea dioxide in the modification of the indigo dyeing process.

Moreover, handwoven fabric dyed with natural indigo dye should be developed for use in other types of products in addition to apparel, such as home textiles, which will create a new market for woven fabric dyed with natural indigo dye. Home textiles are fabric products used in home interior design. Moreover, this substance can be developed for beneficial use in several areas, whether decorating a building, venue, residence, either for practical use or for beauty, such as blankets, mattress sheets, pillowcases, carpets, curtains, placemats, decoration fabric and upholstery fabric, and more. Therefore, home textile products can be considered very important, both as basic needs as well as for commerce. Furthermore, the home textile products of Thailand have improved their designs and quality continuously, in terms of pattern, color, and raw materials, in order to meet the tastes of each market. Today, there is demand growth for home textiles in many Asian markets, such as Japan, Singapore, and Hong Kong, as well as in Europe and America [12]. In the production of home textile products, the general characteristics of home textiles where there must be cleanliness and no defects that might affect their use, should be taken into consideration. These general characteristics can be classified into three categories: safety features, such as being safe from chemical substances; physical features, such as strength and durability in use; and the color fastness feature under different conditions.

This study reviews the construction of woven fabrics dyed with natural indigo dye produced by the indigo-dyed fabric weaving community enterprises of four groups in Thailand. These four groups used a natural indigo dyeing technique in which thiourea dioxide and sodium hydroxide were used in the development of home textile products. Moreover, water repellent finishing, which was used to increase color fastness from rubbing and other uses, was also applied for these products made by these community enterprises. After fabrics had been woven with the skilled weaving of each group, their physical properties, the strength of the woven fabric, and their pilling resistance were then studied. Moreover, the color fastness under different conditions was also studied. The objective of the study was to create suitable design and improved home textile products, according to certain ISO standards for home textile products exported to the European Union [13] in order to raise the standards of the indigo dyed handwoven fabric products of Thailand.

\section{Experimental}

\section{$\underline{2.1 \text { Materials }}$}

Woven fabrics used in this study are made from cotton yarn and yarn made from other plants, such as hemp, linen, and cotton blends. These yarns were dyed with natural indigo using reducing agents of thiourea dioxide and sodium hydroxide.

\subsection{Sample preparation of indigo dyed woven fabrics}

This study surveyed four community enterprises, which had potential, as well as the demands of each group. Their cotton or fiber blended yarns were dyed with natural indigo and later woven into fabrics using their designs. Construction of the woven fabrics were given in detail (Equation 1) and summary in Table 1. All fabric weave patterns were shown in Figure 1.

Fabric construction $=\frac{(\overline{E P I} \times P P I) \times \text { Fabric width }\left(40^{\prime}\right)}{(\text { Warp count } \times \text { Weft count })}$

Plain weave fabric $\mathrm{A}$ made by Entrepreneur A comprised $\mathrm{Ne}$ 20/1 cotton yarn (C) as a warp yarn and $\mathrm{Ne}$ 10/2 cotton and hemp $(\mathrm{C} / \mathrm{H})$ blended yarn at ratio of $65: 35$, woven by handloom of 2 heddles. 
Table 1. Description of the fabric construction

\begin{tabular}{|c|c|c|c|c|}
\hline \multirow{2}{*}{ Code } & \multirow{2}{*}{ Type of weave } & \multirow{2}{*}{$\begin{array}{l}\text { Linear density of warp } \\
\text { yarn }\end{array}$} & \multirow{2}{*}{ Linear density of weft yarn } & Fabric density \\
\hline & & & & EPI $x$ PPI \\
\hline$A$ & \multirow{4}{*}{ Plain weave $1 / 1$} & $\begin{array}{l}\text { Ne 20/1 } \\
\text { Cotton yarn }\end{array}$ & $\begin{array}{c}\mathrm{Ne} 10 / 2 \\
\mathrm{C} / \mathrm{H} \text { blended yarn at } 65: 35\end{array}$ & $43 \times 28$ \\
\hline B1 & & $\begin{array}{c}\text { Ne 20/1 } \\
\text { Cotton yarn }\end{array}$ & $\begin{array}{l}\text { Ne 10/2 } \\
\text { Cotton yarn }\end{array}$ & $100 \times 60$ \\
\hline B2 & & $\begin{array}{c}\text { Ne 20/1 } \\
\text { Cotton yarn }\end{array}$ & $\begin{array}{c}\text { Ne } 20 / 2 \\
\text { Cotton yarn }\end{array}$ & $56 \times 41$ \\
\hline B3 & & $\begin{array}{c}\text { Ne } 7 / 1 \\
\mathrm{C} / \mathrm{L} \text { blended yarn at } 65: 35\end{array}$ & $\begin{array}{c}\mathrm{Ne} 10 / 1 \\
\mathrm{C} / \mathrm{H} \text { blended yarn at } 60: 40\end{array}$ & $60 \times 50$ \\
\hline $\mathrm{C}$ & Twill 2/2 & $\begin{array}{l}\text { Ne } 7 / 1 \\
\text { Cotton yarn }\end{array}$ & $\begin{array}{l}\text { Ne } 7 / 1 \\
\text { Cotton yarn }\end{array}$ & $45 \times 52$ \\
\hline $\mathrm{D}$ & Plain weave $1 / 1$ & $\begin{array}{l}\text { Ne } 20 / 1 \\
\text { Cotton yarn }\end{array}$ & $\begin{array}{l}\text { Ne } 20 / 1 \\
\text { Cotton yarn }\end{array}$ & $107 \times 107$ \\
\hline
\end{tabular}

Entrepreneur B produced 3 woven fabrics by handloom of 2 heddles as follows:

- Plain weave fabric B1 was woven using Ne 20/1 cotton yarn (C) as a warp yarn and Ne 10/2 cotton yarn (C) as a weft yarn.

- Plain weave fabric B2 was woven using Ne 20/1 cotton yarn (C) as a warp and a weft yarn.

- Twill weave 2/2 fabric B3 was made from $\mathrm{Ne} 7 / 1,7 / 2$ cotton and linen (C/L) blended yarn at ratio of 65:35 as a warp yarn woven alternately into a fabric strip of 5 centimeters. For the weft yarn, Ne 10/1 cotton and hemp $(\mathrm{C} / \mathrm{H})$ blended yarn at a ratio of 60:40 was used. The composition of all fibers for this fabric was $47.5 \%$ cotton, $32.5 \%$ linen, and $20 \%$ hemp fiber. Twill weave fabric was woven with a shuttle loom, Ishikawa Dobby brand.

Entrepreneur C produced 7 woven fabrics with $\mathrm{Ne} 7 / 1$ cotton yarn dyed with natural indigo yarn using environmentally friendly techniques with thiourea dioxide as a warp yarn. Then $\mathrm{Ne} 7 / 1$ cotton yarn (C) as a weft yarn was used for woven twill fabric with a loom of 4 heddles. As for patterns of fabrics, yarns were woven as twill $2 / 2$, with 7 patterns: $\mathrm{C} 1-\mathrm{C} 7$, as prototype samples. These samples had woven fabric construction of twill 2/2 pattern as shown by woven fabric C1-C7 (Figure 1), each with different yarn density of warp yarn and weft yarn as indicated by woven fabric construction in Table 1.

Plain weave fabric $D$ made by Entrepreneur $D$ comprised Ne 20/2 rayon yarn (R) as a warp and weft yarn, which was later woven with a loom of 4 heddles following woven fabric construction as shown in Table 1.

The cover factor of each fabric was calculated as Equation 2

$$
\text { Cover factor }=\left(\frac{E P I}{\sqrt{\text { Warp count }}}+\frac{P P I}{\sqrt{\text { weftcount }}}\right) \times
$$

Correction factor for plain weave $=1$

Correction factor for $2 / 2$ Twill weave $=0.7469$

\subsection{Study of physical and mechanical properties of indigo dyed woven fabric}

The physical and mechanical properties of woven fabric samples taken from each group were studied. They are yarn numbers according to ISO 7211-5: 1994, fabric weight per unit area according to ISO 3801-1977, threads/inch according to ISO 7211-2: 1984. Breaking force of the woven fabric was characterized according to ISO 13934-1: 1999 with a tensile testing machine (Shimadzu AGS-J, Japan). Samples were cut into $160 \mathrm{~mm} \times 25 \mathrm{~mm}$ and the speed of testing with a gauge length of $75 \mathrm{~mm}$ was set for breaking within $20 \mathrm{~s}$. Tearing strength was analyzed by a tensile testing machine (Shimadzu AGS-X 10N-10 kN, Japan) according to ISO 13937-2: 2000 standard. Fabric samples were cut into $200 \mathrm{~mm}$ x $50 \mathrm{~mm}$. Each sample was cut with a $100 \mathrm{~mm}$ notch parallel to the length direction from the middle of width direction. Pilling resistance according to ISO 12945 Part 2-2000 was evaluated.

\subsection{Study of color fastness of indigo dyed woven fabrics under different conditions}

Color fastness of indigo dyed woven fabrics under different conditions was conducted. Woven fabric samples of each group were evaluated according to the standard methods as follows here: color fastness to washing according to ISO105-C06 (A1S.): 2010, color fastness to perspiration according to ISO 


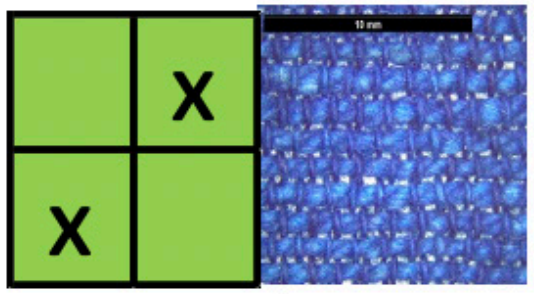

A

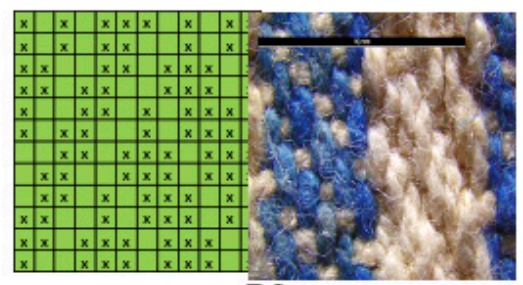

B3

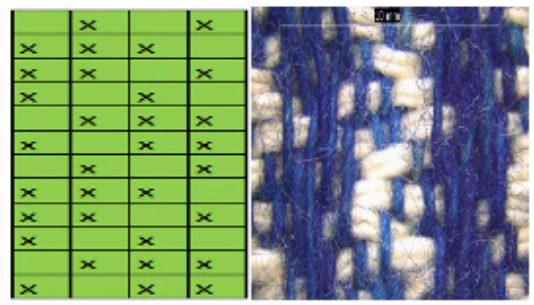

C3

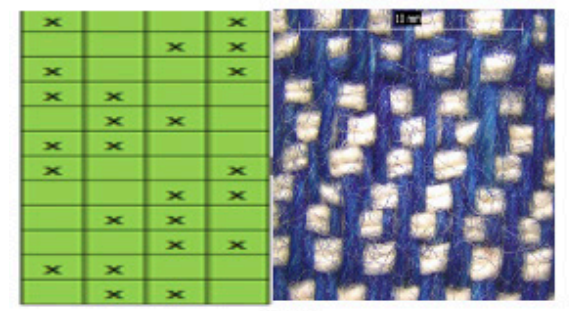

C6

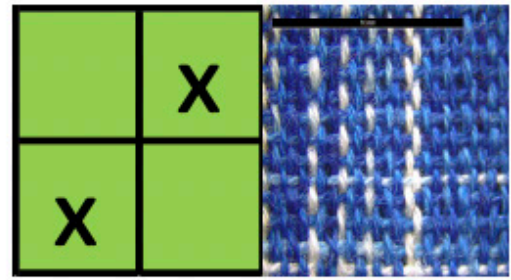

B1

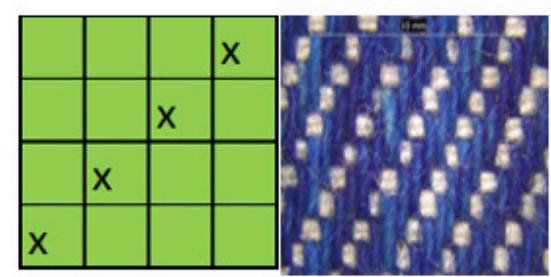

C1

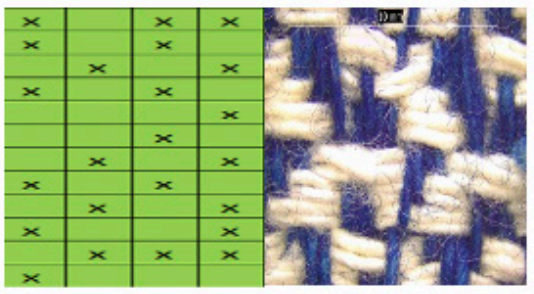

C4

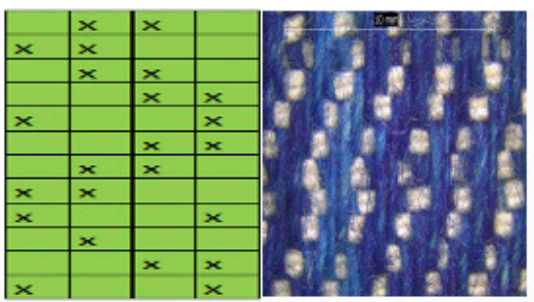

C7

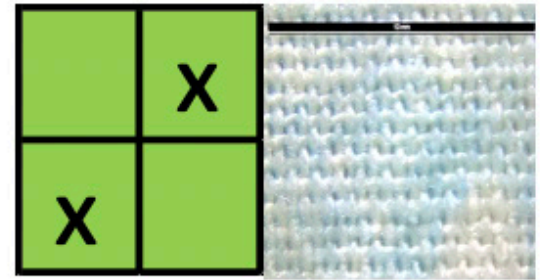

B2

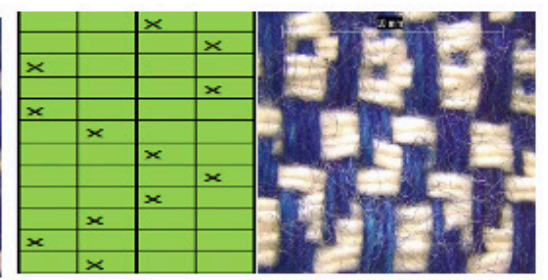

$\mathrm{C} 2$

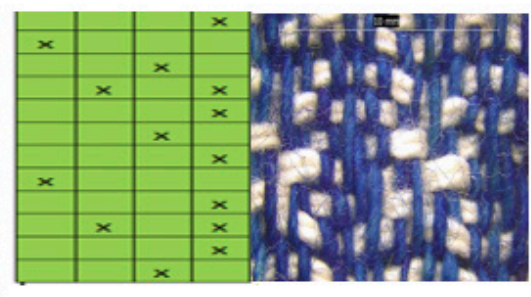

C5

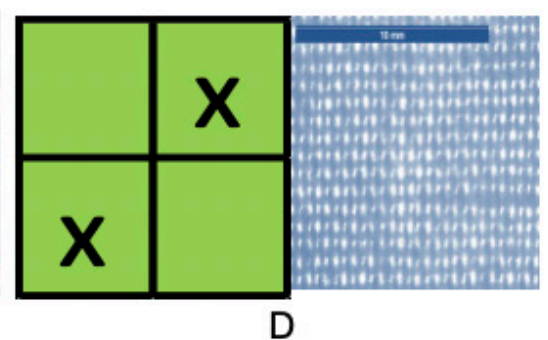

Figure 1. Weaving patterns of indigo dyed woven fabrics.

105-E04: 2013, color fastness to water according to ISO 105E01: 2010, color fastness to rubbing according to ISO 105X12: 2001 and color fastness to light according to ISO 105B02: 1994. The change and staining of the indigo dyed woven fabrics under different conditions were compared using a grayscale rating, ranging from 1 (very poor), 2 (poor), 3 (fair), 4 (good) to 5 (excellent).

\subsection{Finishing for home textile products of indigo dyed woven fabric}

The indigo dyed woven fabrics produced from each entrepreneur were representative for development of four prototype products. These woven fabrics need to finish with polytetrafluoroethylene as a water repellent agent for home textile products. This water repellent agent at concentration of $150 \mathrm{~g} / \mathrm{L}$ was finished on these indigo dyed woven fabrics using pad dry cure method at $70 \%$ pick-up and drying at temperature of $105^{\circ} \mathrm{C}$ for 1 minute. Then the treated woven fabrics were cured at temperature of $160^{\circ} \mathrm{C}$ for 5 minutes. Later, all finished woven fabrics were tested according to the water repellency standard AATCC 22-2014.
The finished woven fabrics no. A, B2, C1 and D were designed for creation of a collection prototype for a spa room in a hotel, depending on their characterization.

\section{Results and discussion}

\subsection{Physical and mechanical properties of indigo dyed woven fabrics}

Table 2 indicates physical and mechanical properties of indigo dyed woven fabrics. Woven fabrics of Entrepreneur A (Code A) were tested for tensile strength. It was found that weft yarn is stronger than warp yarn. This is because Ne 20/1 cotton yarn was used as warp yarn, whereas $\mathrm{Ne} 20 / 2$ cotton/hemp blended yarn, which is thicker yarn, was used as a weft yarn. As a result, weft yarn had higher tensile strength and tear strength than warp yarn, which is made from cotton. It was found that with abrasion cycles of 4,000 revolutions, the pilling resistance would have the value $\geq 4$, which means that the occurrence of pilling is low. According to the ISO standards test of home textile products of the European Union [13] for pillowcase and upholstery fabrics, it is set that fabric construction should 
have tensile strength greater than $180 \mathrm{~N}$ and tear strength greater than $1000 \mathrm{cN}$, for both weft and warp direction. Woven fabric code A passed all of these standard criteria. As for the pilling resistance, it should have the value of 4 , which would exceed the set standard, and can be used to make bed sheets, pillowcases, duvet covers, tablecloths, placemats, and seat cushions.

Woven fabrics of Entrepreneur B, for code B1 and B2, were woven on a hand loom of 2 heddles. Woven fabric B3 was woven by machine loom. The results of the mechanical properties of these woven fabrics were shown in Table 2. It was found that tensile strengths in both directions of woven fabrics were in the range of 355-534 N, and tear strengths in both directions of woven fabrics were in the range of $15.98-98.48 \mathrm{~N}$. As for the pilling resistance, given the abrasion cycles of 4,000 revolutions of woven fabric $\mathrm{B} 1$ and $\mathrm{B} 2$, it was found to have the value $\geq 4$, indicating that there will be no pilling. According to the EU home textile standard [13], with the exception of woven fabric B3, which has the pilling resistance value of 2 and is more suitable for products with less abrasion or can be finished to increase the durability of the fabric, it was found in general that woven fabric B1 and B2 can be used to produce home textile products, that is, curtains, bed sheets, pillowcases, duvet covers, tablecloths, placemats, and seat cushions, which is the same as woven fabric $A$.

As for indigo dyed handwoven denims of $\mathrm{C} 1-\mathrm{C} 7$, they have the following properties: weights of the woven fabrics of each type have different values in the range between 363-495 g/m², depending upon the design of weft or warp. As for the results of tensile strengths of fabrics, it was found that woven fabrics of all 7 patterns had similar tensile strengths of warp yarn, at approximately $500 \mathrm{~N}$, whereas tensile strengths of weft yarn would depend upon the type of pattern. Pattern C4 would have the highest tensile strengths as it is an alignment of the 4 weft yarns enhancing its maximum strength. Regarding the test of color fastness under different states as shown in Table 2 , it indicates that all 7 patterns have similar color fastness properties, that is, they all have the same "good" level of color fastness (color change) to washing, perspiration, and to water. As for color fastness to staining on different types of fibers, it was found to be in "good" and "excellent" levels, except for color fastness to perspiration, in the color staining on different types of fibers, especially for acetate and nylon, which have lower property levels than the others. Regarding the color fastness to light, it was found to have the value exceeding 5 , meaning able to withstand artificial light at the level of "good." In case of color fastness to rubbing, color fastness in dry conditions was found to be at "good" and "excellent" levels, whereas under wet conditions, color fastness was found to be low to medium quality, due to their natural and dark color. Woven fabrics treated with water-repellent finishing were evaluated for their color fastness to rubbing, and it was found that the value of color fastness in wet conditions greatly improved (from 2-3 to 3-4 value). This is in accordance with the result of Giannoulis et al. [14] and Schindler and Hauser [15], who found that applying finishing to the fabrics would help to improve the color fastness property of the fabric. However, in making a fabric prototype, only woven fabric $\mathrm{C} 1$ with denim pattern due to smoother fabric surface, was woven using a shuttle loom (Sakamoto) and finishing was applied. The fabric was made into a prototype for partition screen and cushion upholstery due to the fabric strengths, which are suitable for these products.

Woven fabrics of Entrepreneur D for code D were tested for tensile and tear strength as shown in Table 2. It was found that tensile strength of woven fabric $D$ for both warp and weft direction was in the range of 634-755 $\mathrm{N}$ and its tear strength was in the range of $34.32-35.37 \mathrm{~N}$. The value of pilling resistance, with rubbing cycles of 4,000 revolutions, was found to be around 3-4, which indicated that the occurrence of pilling would be average to low. This is the same as the EU home textile standard [13], which states woven fabric $C$ is suitable for sofa upholstery.

The cover factor defined a number that indicates the extent to which the area of a fabric is covered by one set of yarns. Covering power refers to the ability of an item to occupy space or to cover an area. A fabric with better cover will be warmer, look and feel more substantial, and be more durable, as shown in Table 2. For categories of fabric $\mathrm{C}$, there are similar cover factors; only woven fabric $\mathrm{C} 1$ was representative to measure tear strength and pilling properties.

\subsection{Color fastness of woven fabrics under different conditions}

As for color fastness, shown in Tables 3 and 4, it was found that these woven fabrics (A, B1, B2, B3, C1, and D) have color fastness to washing, perspiration, and to water at "good" and "excellent" levels. Color fastness to color change and color staining on different types of fibers were also found to be at good and excellent levels. This indicates that indigo color and cotton yarn or cellulose fibers are well bonded, due to the hydrogen bond [16,17], with the exception of woven fabric C1 and D. As for color fastness to perspiration, in alkaline conditions, the color fastness had declined. In these conditions color change was at "fair" to "good" levels and color staining on different fibers was at the "good" level. Regarding color fastness to rubbing, it was found that color fastness under dry conditions of each fabric was at "good" to "excellent" levels. As for wet conditions, woven fabrics A and B1 were found to have low to average values of color fastness, as can be explained by the characteristic of indigo, which was insoluble $[17,18]$. Woven fabrics B2, B3, C1 and D were found to have values of color fastness at "good" levels because indigo is a natural color, so its color fastness would be lower than that of synthetic color [6]. Moreover, the shade of dyed color and the dyeing process can also affect color fastness. Color fastness to light was also found to a have a value more than 5 , which indicated that these fabrics were able to withstand artificial light at a good level. According to the EU home textile standard [13], it was found that color fastness under different conditions passed all the standard criteria, except for color fastness to rubbing under wet conditions, where woven fabrics $A, B 1$, and $C 1$ did not pass this criterion. Research works of Ginannoulis et al. [14], as well as Schindler and Hauser [15], stated that fabric finishing will improve color fastness under these conditions. 
Table 2. Physical and mechanical properties of indigo woven fabrics

\begin{tabular}{|c|c|c|c|c|c|c|c|c|}
\hline Code & Direction & $\begin{array}{l}\text { Linear } \\
\text { density } \\
\text { (Ne) }\end{array}$ & $\begin{array}{l}\text { Yarn density } \\
\text { (thread/inch) }\end{array}$ & $\begin{array}{l}\text { Fabric weight } \\
\qquad\left(\mathrm{g} / \mathrm{m}^{2}\right)\end{array}$ & $\begin{array}{l}\text { Cover } \\
\text { factor }\end{array}$ & $\begin{array}{c}\text { Tensile } \\
\text { strength }(\mathrm{N})\end{array}$ & $\begin{array}{l}\text { Tear } \\
\text { strength } \\
\text { (N) }\end{array}$ & $\begin{array}{c}\text { Pilling } \\
4,000 \\
(\mathrm{rev})^{*}\end{array}$ \\
\hline \multirow{2}{*}{$A$} & Warp & $20 / 1$ & 41 & \multirow{2}{*}{250} & \multirow{2}{*}{15.5} & 300.00 & 14.12 & \multirow{2}{*}{4} \\
\hline & Weft & $10 / 2$ & 51 & & & 375.00 & 22.20 & \\
\hline \multirow{2}{*}{ B1 } & Warp & $20 / 1$ & 100 & \multirow{2}{*}{193} & \multirow{2}{*}{34.0} & 452.80 & 36.57 & \multirow{2}{*}{4} \\
\hline & Weft & $10 / 1$ & 60 & & & 355.90 & 30.37 & \\
\hline \multirow{2}{*}{ B2 } & Warp & $20 / 1$ & 56 & \multirow{2}{*}{219} & \multirow{2}{*}{13.8} & 534.80 & 16.32 & \multirow{2}{*}{5} \\
\hline & Weft & $20 / 1$ & 41 & & & 415.10 & 15.98 & \\
\hline \multirow{2}{*}{ B3 } & Warp & $7 / 2$ & 60 & \multirow{2}{*}{512} & \multirow{2}{*}{27.1} & 454.40 & 97.82 & \multirow{2}{*}{2} \\
\hline & Weft & $10 / 1$ & 50 & & & 522.00 & 98.48 & \\
\hline \multirow{2}{*}{$\mathrm{C} 1$} & Warp & $7 / 1$ & 45 & \multirow{2}{*}{363} & \multirow{2}{*}{27.1} & 503.33 & 173.31 & \multirow{2}{*}{4} \\
\hline & Weft & $7 / 1$ & 52 & & & 766.67 & 65.55 & \\
\hline \multirow{2}{*}{$\mathrm{C} 2$} & Warp & $7 / 1$ & 45 & \multirow{2}{*}{375} & \multirow[t]{2}{*}{27.7} & 502.86 & & \\
\hline & Weft & $7 / 1$ & 52 & & & 707.14 & & \\
\hline \multirow{2}{*}{ C3 } & Warp & $7 / 1$ & 43 & \multirow{2}{*}{408} & \multirow[t]{2}{*}{26.0} & 473.57 & & \\
\hline & Weft & $7 / 1$ & 48 & & & 716.43 & & \\
\hline \multirow{2}{*}{$\mathrm{C} 4$} & Warp & $7 / 1$ & 42 & \multirow{2}{*}{495} & \multirow[t]{2}{*}{28.0} & 498.00 & & \\
\hline & Weft & $7 / 1$ & 56 & & & 960.00 & & \\
\hline \multirow{2}{*}{ C5 } & Warp & $7 / 1$ & 45 & \multirow{2}{*}{382} & \multirow[t]{2}{*}{26.0} & 446.00 & & \\
\hline & Weft & $7 / 1$ & 46 & & & 680.00 & & \\
\hline Ca & Warp & $7 / 1$ & 43 & 275 & 26.6 & 476.00 & & \\
\hline 0 & Weft & $7 / 1$ & 50 & (5) & & 688.00 & & \\
\hline 7 & Warp & $7 / 1$ & 42 & 100 & 27.1 & 478.00 & & \\
\hline שו & Weft & $7 / 1$ & 53 & 400 & & 810.00 & & \\
\hline ח & Warp & $20 / 2$ & 107 & 075 & 01 & 634.50 & 34.32 & ? \\
\hline$\sigma$ & Weft & $20 / 2$ & 107 & 210 & 21.4 & 755.00 & 35.37 & $8-4$ \\
\hline
\end{tabular}

$\mathrm{C} 1$ is representative for testing tearing strength and pilling for category of woven fabric $\mathrm{C}$ due to similar pattern design with smoother surface.

${ }^{*}$ rev $=$ revolution

Therefore, water repellent finishing was applied to woven fabrics $\mathrm{A}, \mathrm{B} 1$, and $\mathrm{C} 1$, and afterward the color fastness to rubbing was tested. It found that all fabrics have the value of $3-4$, which is "average" to "rather good." In comparison, prior to finishing, the color fastness to wet rubbing of woven fabrics A, B1 and C1, was between 2-3, that is, "poor" to "fair" level; therefore, it can be indicated that water repellent finishing will help increase the value of color fastness to rubbing, which is in accordance with the research work of Giannoulis et al. [14].

\subsection{Properties after water repellent finishing of indigo dyed woven fabrics}

Woven fabrics of each group were used to make products and finishing. Their properties were later tested and the results are shown in Table 5, classified into different groups and fabrics used to promote different products as follows:
Woven fabric A, which was a cotton/hemp blended yarn as weft direction, in weaving line pattern with different widths, is tailored into a Japanese yukata coat. Furthermore, plain weave fabric dyed with indigo was used to make trousers. In addition, this fabric can be sewn to make backrest pillows of the size $45 \times 45 \mathrm{~cm}^{2}$, and $35 \times 20 \mathrm{~cm}^{2}$. After water repellent finishing, the Japanese yukata coat and backrest pillow had water repellency at a rating of 95 , which their surface had a lotus effect.

Entrepreneur B applied woven fabric B2 to make upholstery fabric for a Louis-style chair: a seat cushion and backrest. This fabric also had water repellent finishing applied. Its water repellency value was 75 , which means that the fabric surface would be wet only in the area in which water was sprayed. Thus the most suitable use for this type of fabric was for meeting rooms and for luxury events 
Table 3. Color fastness of indigo woven fabrics to washing, water, and perspiration

\begin{tabular}{|c|c|c|c|c|c|c|c|}
\hline \multicolumn{2}{|c|}{ Color fastness to washing } & \multicolumn{6}{|c|}{ Colour staining } \\
\hline Code & Colour change & Acetate & Cotton & Nylon & Polyester & Acrylic & Wool \\
\hline A & $4-5$ & $4-5$ & $4-5$ & $4-5$ & $4-5$ & $4-5$ & $4-5$ \\
\hline B1 & 4 & $4-5$ & $4-5$ & $4-5$ & $4-5$ & $4-5$ & $4-5$ \\
\hline B2 & $4-5$ & $4-5$ & $4-5$ & $4-5$ & $4-5$ & $4-5$ & $4-5$ \\
\hline B3 & $4-5$ & $4-5$ & $4-5$ & $4-5$ & $4-5$ & $4-5$ & $4-5$ \\
\hline $\mathrm{C} 1$ & $4-5$ & $4-5$ & $4-5$ & $4-5$ & $4-5$ & $4-5$ & $4-5$ \\
\hline $\mathrm{D}$ & $4-5$ & $4-5$ & $4-5$ & $4-5$ & $4-5$ & $4-5$ & $4-5$ \\
\hline \multicolumn{8}{|c|}{ Color fastness to water } \\
\hline A & $4-5$ & $4-5$ & $4-5$ & $4-5$ & $4-5$ & $4-5$ & $4-5$ \\
\hline B1 & 4 & $4-5$ & $4-5$ & $4-5$ & $4-5$ & $4-5$ & $4-5$ \\
\hline B2 & $4-5$ & $4-5$ & $4-5$ & $4-5$ & $4-5$ & $4-5$ & $4-5$ \\
\hline B3 & $4-5$ & $4-5$ & $4-5$ & $4-5$ & $4-5$ & $4-5$ & $4-5$ \\
\hline $\mathrm{C} 1$ & $4-5$ & $4-5$ & $4-5$ & $4-5$ & $4-5$ & $4-5$ & $4-5$ \\
\hline $\mathrm{D}$ & $4-5$ & $4-5$ & $4-5$ & $4-5$ & $4-5$ & $4-5$ & $4-5$ \\
\hline \multicolumn{8}{|c|}{ Color fastness to perspiration (Acid) } \\
\hline$A$ & 4 & $4-5$ & $4-5$ & $4-5$ & $4-5$ & $4-5$ & $4-5$ \\
\hline B1 & $4-5$ & $4-5$ & $4-5$ & $4-5$ & $4-5$ & $4-5$ & $4-5$ \\
\hline B2 & $4-5$ & $4-5$ & $4-5$ & $4-5$ & $4-5$ & $4-5$ & $4-5$ \\
\hline B3 & $4-5$ & $4-5$ & $4-5$ & $4-5$ & $4-5$ & $4-5$ & $4-5$ \\
\hline C1 & 4 & 4 & $4-5$ & 4 & $4-5$ & $4-5$ & $4-5$ \\
\hline $\mathrm{D}$ & $4-5$ & $4-5$ & $4-5$ & $4-5$ & $4-5$ & $4-5$ & $4-5$ \\
\hline \multicolumn{8}{|c|}{ Color fastness to perspiration (Alkaline) } \\
\hline A & 4 & $4-5$ & $4-5$ & $4-5$ & $4-5$ & $4-5$ & $4-5$ \\
\hline B1 & 4 & $4-5$ & $4-5$ & $4-5$ & $4-5$ & $4-5$ & $4-5$ \\
\hline B2 & 4 & $4-5$ & $4-5$ & $4-5$ & $4-5$ & $4-5$ & $4-5$ \\
\hline B3 & 4 & $4-5$ & $4-5$ & $4-5$ & $4-5$ & $4-5$ & $4-5$ \\
\hline C1 & 4 & 4 & $4-5$ & 4 & $4-5$ & $4-5$ & $4-5$ \\
\hline D & $3-4$ & 4 & 4 & 4 & 4 & 4 & 4 \\
\hline
\end{tabular}

Color change or color strain of grey scales before and after wash fastness test: $5=$ excellent, $4=$ good, $3=$ fair, $2=$ poor, $1=$ very poor.

Woven fabric $\mathrm{C} 1$ made by Entrepreneur $\mathrm{C}$ was cotton yarn with a twill pattern and dyed with natural indigo dye with thiourea dioxide as a reducing agent in the natural indigo dyeing process. Water repellent finishing was applied, and it then had the value of water repellency at a rating of 90 . This fabric surface absorbed only a few drops of water; it can be used to make furniture upholstery.

The results of finishing tests, according to the standard of AATCC and ASTM, have proven that after finishing was added to the products, such products will have more diversified functionalities and more benefits. The finishes will make them safer to use. Moreover, it will also add value to the textile products. However, such finishes must not contain more than the level of $0.1 \%$ of the finishing chemical, which may cause cancer, genetic mutation, effect on the reproductive system, and toxicity to the environment, as indicated by Directive 67/548/EEC.

From all characterizations of woven fabric mentioned above (Tables 3 and 4), woven fabrics A, B2, C1, and D can be used to produce different home textile products, as shown in Figure 2 , and can be used as a prototype of products used in the interior design of hotel spas.

This study applied natural indigo dyeing with reducing agents of thiourea dioxide and sodium hydroxide, which are environmentally friendly, and can be applied to dyeing at industry level, which required consistency and less time in the dyeing process. This included yarn dyeing of blended yarn 
Table 4. Color fastness to rubbing and light of indigo woven fabrics

\begin{tabular}{|c|c|c|c|}
\hline \multirow{2}{*}{ Code } & \multicolumn{2}{|c|}{ Colour fastness to rubbing } & \multirow{2}{*}{ Colour fastness to light* } \\
\cline { 2 - 4 } & $\begin{array}{c}\text { Dry } \\
\text { (Warp \& Weft) }\end{array}$ & $\begin{array}{c}\text { Wet } \\
\text { (Warp \& Weft) }\end{array}$ & $>5$ \\
\hline A & $4-5$ & $2-3$ & $>5$ \\
\hline B1 & $4-5$ & $2-3$ & $>5$ \\
\hline B2 & $4-5$ & 4 & $>5$ \\
\hline B3 & $4-5$ & 4 & $>5$ \\
\hline C1 & 4 & $2-3$ & $>5$ \\
\hline D & $4-5$ & 4 & \\
\hline
\end{tabular}

Color change or color stain of grey scales before and after wash fastness test: $5=$ excellent, $4=$ good, $3=$ fair, $2=$ poor, $1=$ very poor.

${ }^{*}$ Color change of sample with eight level blue wool reference standard, before and after light fastness test,: $8=$ excellent , $7=$ extremely good, 6 = very good, 5 = good, 4 = rather good, 3 = average, $2=$ low, $1=$ poor

Table 5. Water repellency of indigo woven fabrics

\begin{tabular}{|c|c|c|c|}
\hline & \multirow{2}{*}{ Fabric no./Product photo } & \multicolumn{2}{|c|}{$\begin{array}{l}\text { Water repellency (AATCC 22-2014)* } \\
\text { (Rating) }\end{array}$} \\
\hline & & Untreated & Treated \\
\hline A & & 75 & 95 \\
\hline B2 & & 0 & 75 \\
\hline C1 & 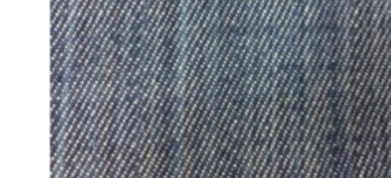 & 60 & 90 \\
\hline
\end{tabular}

such as cotton, hemp, and linen fibers to be used in designing home textile products; application of finishing, such as water repellents, oil repellents, and rubbing resistance substances, was also studied. This made indigo dyed woven fabric products withstand contaminations of water, oil, and rubbing, and made them more suitable for the design of home textile products. It should be: Please add one sentence

Moreover, monosaccharides (glucose, fructose and galactose) and reducing disaccharides (lactose and maltose) may use for green reducing agents applied for the indigo-dyed fabric weaving community enterprises which will give oppotunity for green dyeing technique [19].

\section{CONCLUSIONS}

From the study of woven fabric construction for home textile products, it was found that woven fabrics of different patterns, were woven according to the expertise and suitability of each group. The physical and mechanical properties and color fastness passed the requirement set by the ISO standard for EU home textile products for tensile strength, tear strength, 


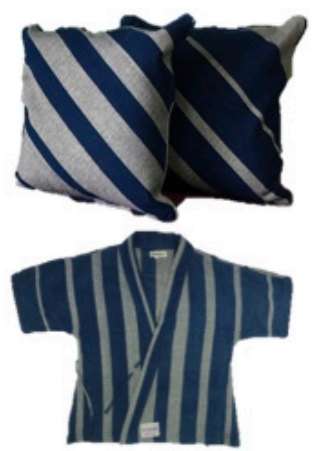

A

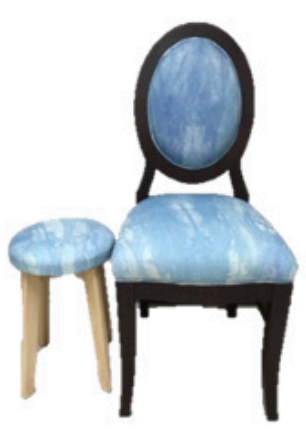

B

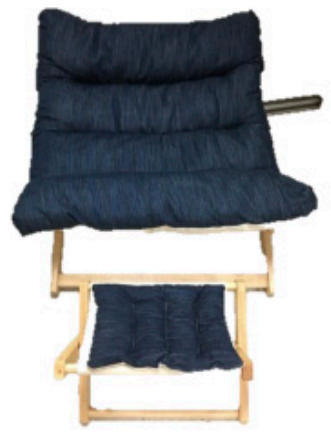

C

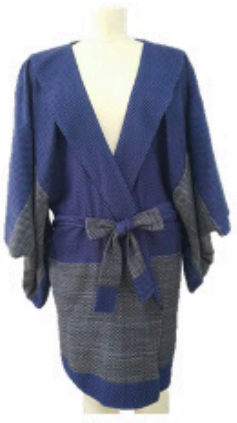

D
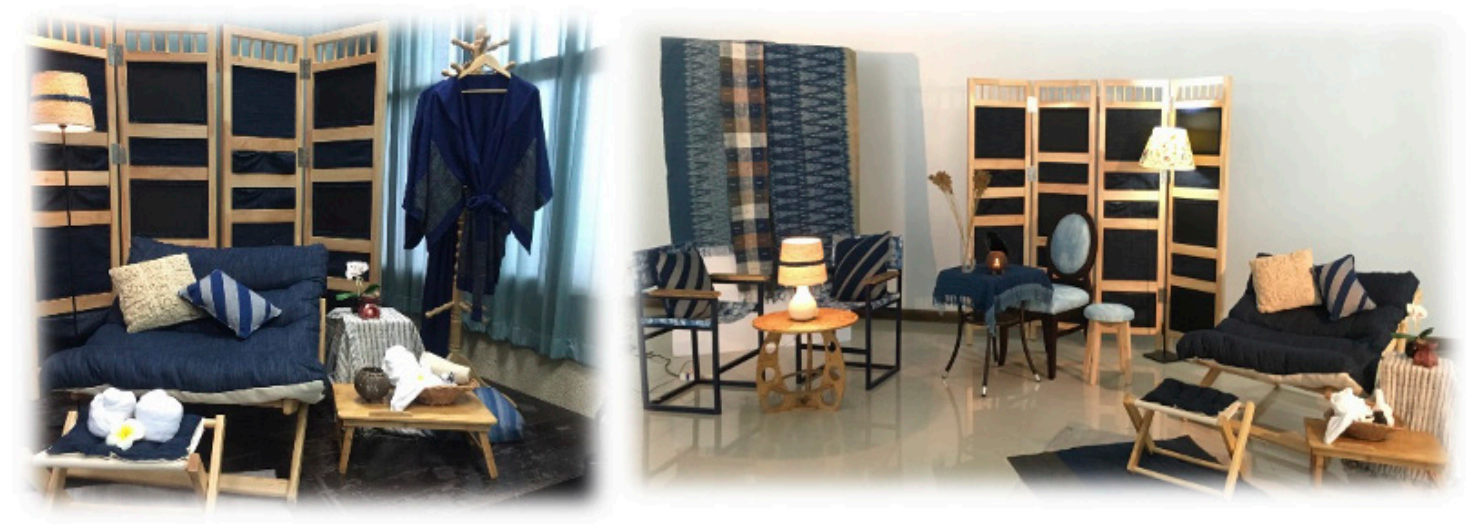

E

Figure 2. Products of home textiles produced by 4 groups of community enterprises and SMEs. A: Entrepreneur A; B: Entrepreneur B; C: Entrepreneur C; D: Entrepreneur D; E: Prototype model of indigo-dyed textile product for home textiles in spa rooms.

pilling resistance, color fastness to washing, color fastness to water, and color fastness to light. However, the requirement which not all fabrics passed is color fastness to rubbing in wet conditions. Natural color and indigo color, which use the dyeing technique of reducing agents at room temperaturę, have less color fastness than that of synthetic color. Furthermore, the shade of color used, the dyeing proces, and the washing of color will affect color fastness. When water repellent finishing is applied to the fabric, this will help increase the value of color fastness of the products.

The most appropriate construction of indigo woven fabric of home textile products used in this research is woven fabric with a twill pattern, which has high strength. Furthermore, fabrics with lots of textures will not be suitable to make high contact products because it would create the problem of pilling. Therefore, the type of woven fabric selected for use will depend on the type of products. Moreover, the type of yarn, yarn number, and number of threads are factors that would affect the properties of woven fabrics. In natural indigo dyeing, it is necessary to have finishing in order to improve the color fastness property and to pass the export standard of each country. In designing home textile products, not only suitable construction but also aesthetic factors, style, and the distinctive character of the product matter. This will help enhance the charms of indigo fabrics of Thailand. Indigo fabrics can be used in many diverse products and are favorites among home textile products, such as backrest pillows, bed runners, wall decorative fabrics or curtains, in addition to scarves, shawls, and cloth tailoring.

\section{ACKNOWLEDGEMENTS}

The support for this research provided by the National Research Council of Thailand and Thailand Science Research and Innovation is greatly appreciated. Authors gratefully acknowledge the help of Rajamangala University of Technology Phra Nakhon (RMUTP), Thailand, for supporting this research.

\section{References}

[1] Poulin, J. (2007). Identification of indigo and its degradation products on a silk textile fragment using gas chromatography-mass spectrometry. Journal of the Canadian Association for Conservation, 32, 47-56.

[2] Mongkholrattanasit, R., Klaichoi, C., Mudchiew, O., Punrattanasin, N., Sasivatchutikool, N., Rungruangkitkrai, N. (2014). Effect of ferrous sulfate to improve UV-protection property of cotton fabric dyed with natural indigo. Advanced Materials Research, 1030-1032, 418-421.

[3] Ticha, M. B., Meksi, N., Drira, N., Kechida, M., Mhenni, M.F. (2013). A promising route to dye cotton by indigo with an ecological exhaustion process: A dyeing process optimization based on a response surface methodology. Industrial Crops and Products, 46, 350-358. 
[4] Hauser, P., Tabba, A. H. (2001). Improving the environmental and economic aspects of cotton dyeing using a cationised cotton. Colour Technology, 117, 282-288.

[5] Chollakup, R., Smitthipong, W., Tantatherdtam, R. (2013). Application of layer by layer deposition (LBL) of oppositely charged polyelectrolyte on silk fibre. In 2013 International Textiles and Costume Congress, 2013. Bangkok, Thailand.

[6] Wittayakarn, S., Sidarkote, R., Rungruangkitkrai, N., Mongkholrattanasit, R., Nithithongsakol, N., Chollakup, $R$. (2018). Natural indigo dyeing using glucose as reducing agent in alkaline condition for cotton yarn. In The 9th RMUTP International Conference on Science, Technology and Innovation for Sustainable Development (Section: Textiles and Clothing Sustainability, 2018, 177). Bangkok, Thailand.

[7] Khan, M.R., Uddin, Z., Hossain, D. (2014). Eco-sustainable process development for indigo dye by using natural reducing agents. Middle East Journal Science Research, 22 (7), 1090-1095.

[8] Shin, Y., Choi, M., Yoo, D.I. (2014). Eco-friendly indigo reduction using bokbunja (Rubus coreanus Miq.) sludge. Fashion and Textiles, 1(6), 1-8.

[9] Yoo, D.I., Shin, Y. (2020). Application of persimmon (Diospyros kaki L.) peel extract in indigo dyeing as an eco-friendly alternative reductant. Fashion and Textiles, 7(28), 1-9.

[10] Carlough, M. S. (1999). Exhaust dyeing process for sulphur dyes. Patent No.US5873912A. (United States). Febuary 23, 1999.

[11] Luo, Q., Ren, T., Shen, H., Liang, D., Zhang, J. (2017).
Comparison of thermal hazards of sodium dithionite and thiourea dioxide from thermal analysis (Dsc-Tg), smallscale self-heating experiments and FTIR smoke gas analysis. Fire Safety Journal, 92, 91-97.

[12] Chairatanachatchawal, C. (2008). Home Textiles. Retrieved November 8, 2017. Web site: www.ttistextiledigest.com.

[13] Das, S. (2010). Performance of home textile (1 ${ }^{\text {st }}$ ed.). Woodhead Publishing India Pvt. Ltd., New Delhi.

[14] Giannoulis, A., Karanikas, E., Eleftheriadis, I., Nikolaidis, N., Tsatsaroni, E. (2016). Colour fastness to crocking improvement of indigo and sulphur dyed cellulosic fibers. International Journal of Advanced Research in Chemical Science, 3, 44-52.

[15] Schindler W. D., Hauser, P. J. (2004). Chemical Finishing of Textiles (1 $1^{\text {st }}$ ed.). The Textile Institute, Woodhead Publishing in Abington, Cambridge.

[16] Wannajun, S., Srihanam, P. (2012). Development of Thai textile products from bamboo fiber fabrics dyed with natural indigo. Asian Journal of Textile, 2(3), 44-50.

[17] Mongkholrattanasit, R., Klaichoi, C., Sasithorn, N., Changmuang, W., Manarungwit, K., Maha-In, K., Ruenma, P., Boonkerd, N., Sangaphat, N., Pangsai, M. (2018). Screen printing on silk fabric using natural indigo. Vlakna a Textile, 3 (25), 51-56.

[18] Son, Y. A., Hong, J. P., Kim, T. K. (2004). An approach to the dyeing of polyester fiber using indigo and its extended wash fastness properties. Dyes and Pigments, 61(3), 263272.

[19] Saikhao, L., Setthayanond, J., Karpkird, T., Bechtold,T., Suwanruji, P. 2018. Green reducing agents for indigo dyeing on cotton fabrics. Journal of Cleaner Production,197(1), 106-113. 